\title{
Evaluating the Frequency of Clinical and Microscopic Views of Basal Cell Carcinoma in a 10-Year Period
}

\author{
Abdal Kh' $\mathbf{K}^{1}$, Salehinejad $\mathbf{J}^{2}$, Mostafazadeh $\mathbf{S}^{3^{*}}$ \\ ${ }^{I}$ Assistant professor,Oral Pathology Dept, Faculty of Dentistry, Ilam University of Medical Sciences, Ilam, Iran \\ ${ }^{2}$ professor,Oral Pathology Dept, Faculty of Dentistry,Mashhad University of Medical Sciences, Mashhad, Iran \\ ${ }^{3}$ Assistant professor, Oral Pathology Dept, Faculty of Dentistry, Urmia University of Medical Sciences, Urmia, Iran
}

\begin{tabular}{l}
\hline ARTICLE INFO \\
\hline Article Type \\
Original Article \\
Article History \\
Received: April 2016 \\
Accepted: July 2016 \\
ePublished: Oct 2016 \\
\hline
\end{tabular}

\section{Keywords:}

Skin neoplasms, Basal Cell Carcinoma, Cancer

\section{ABSTRACT}

Background and aim: Basal Cell Carcinoma (BCC) is the most common skin neoplasm and the most common type of cancer. Since the incidence of injury is taken into consideration in the pathologic diagnosis, the study of clinical and microscopic views of $\mathrm{BCC}$ is of particular importance. The present study aimed at determining the frequency of clinical and microscopic views of BCC in a 10-year period in Ilam province.

Materials and methods: This study is descriptive. The study population consisted of all the subjects with BCC in the head and neck area referring to the pathology department of Imam Khomeini hospital in Ilam province in a 10-year period. The data were entered into SPSS 19 software and were analyzed using descriptive statistical methods and Chi-Square test.

Results: In the present study, 205 patients were diagnosed with BCC. The maximum and minimum frequency rates of the lesion were detected in the frontal area $(9.23 \%)$ and neck $(8.7 \%)$, respectively. The maximum frequency was related to the nodular type $(57.1 \%)$, while the pigmented variant showed the lowest rate $(8.3 \%)$. Among the evaluated microscopic variants, maximum views were related to the solid-cystic type $(57.1 \%)$, while minimum views were related to the pigmented variant $(37.3 \%)$. There was no significant correlation between the location of the lesion in males and females $(p=0.14)$ or between the location of the lesion and age $(p=0.16)$.

Conclusion: The results of this study showed that the nodular type was the most common clinical variant of BCC, while the least common type was the pigmented variant. The most common histological type was the solid-cystic type, while the pigmented variant was the least common type.

\footnotetext{
Please cite this paper as: Abdal Kh, Salehinejad J, Mostafazadeh S. Evaluating the Frequency of Clinical and Microscopic Views of Basal Cell Carcinoma in a 10-year period.J Res Dent Maxillofac Sci 2016;1(4):39-44
}

\author{
*Corresponding author: \\ Mostafazadeh S \\ Email: mostafazadeh_samira@yahoo.com
}




\section{Introduction:}

The term "head and neck cancer" encompasses various tumors appearing in the throat, larynx, nose, sinuses, and mouth. Malignant tumors in the head and neck may be of epithelial or mesenchymal origin ${ }^{(1)}$ Basal Cell Carcinoma (BCC) is the most common skin neoplasm and the most common type of cancer. This tumor is a primary epithelial malignant lesion with local invasion and slow growth that arises from the basal layer of the skin and its appurtenances. ${ }^{(2)}$ It involves the scalp and neck in about $85 \%$ of cases, and white adults are most frequently involved, especially those with fair skin, blond hair and blue or green eyes over 40 years of age. ${ }^{(3)}$ More than 800,000 new cases of BCC are diagnosed in the United States every year. The incidence of lesions is increasing by $10 \%$ annually worldwide. Generally, the incidence increases with age. ${ }^{(4,5)}$

This cancer mainly occurs after long-term exposure to ultraviolet radiation. Repeated sunburns in childhood, immunosuppressive therapy, arsenic ingestion, and multiple genodermatoses are associated with the formation of BCC. ${ }^{(6)}$ The most common clinical type of the lesion is the ulcerative nodular type, which starts as a stiff and painless papule that grows slowly and causes an expanding wound at the center of the lesion that can destroy the underlying structures if being left untreated..$^{(7)}$ Other clinical and pathological types of the lesion are the pigmented, sclerosing, and superficial types. The treatment methods are excisional surgery, lasers, radiotherapy, and frozen section, and depend on the size and location of the lesions. ${ }^{(8,9)}$ Recurrence of a properly treated $\mathrm{BCC}$ is uncommon, and metastasis is extremely rare. ${ }^{(10)}$ Patients with uncontrolled disease usually lose their lives due to local invasion of the lesion to critical organs. ${ }^{(11)}$ Considering the importance of early detection and the necessity of treating this carcinoma, epidemiological study, timely diagnosis, and quick treatment of the tumor are mandatory. Knowledge about the prevalence of different types of this tumor and their clinical characteristics, such as age, gender predilection, and location of occurrence, helps clinicians to reach a correct diagnosis.

Since the incidence of injury is taken into consideration in the pathological diagnosis, the study of clinical and microscopic views of BCC is of particular importance, as accurate and timely diagnosis of $\mathrm{BCC}$ is crucial. ${ }^{(12)}$ The results of the conducted studies can help in early diagnosis and treatment of the lesions and consequently can prevent further side effects. ${ }^{(13)}$ This study examined the frequency of clinical and microscopic views of BCC in a 10-year period in Ilam province to gather comprehensive information regarding the frequency of clinical and microscopic variants of BCC.

\section{Materials and methods:}

This study is descriptive. All the pathology files of the patients with BCC in the head and neck admitted to, hospitalized and treated in Ilam's Imam Khomeini Hospital from 2004 to 2015 were studied. After selecting the files, the required information such as age, sex, location of the lesion, and microscopic diagnosis of the lesions were recorded in designated tables. Afterwards, the incidence and types of microscopic views of $\mathrm{BCC}$ in the head and neck were examined based on age, sex, location of the lesion and tumor type. Several clinicopathologic variants of BCC have been described. The most common form of this lesion is the nodular BCC which is a firm painless papule that slowly enlarges and develops a central depression and an umbilicated appearance. Pigmented BCC is a noduloulcerative tumor colonized by benign melanocytes. Sclerosing type (morpheaform) of BCC often mimics scar tissue. The superficial BCC is comprised of multiple and well-demarcated, erythematous scaly patches that may be clinically misdiagnosed as psoriasis..$^{(1,2)}$ The solid-cystic type of BCC is comprised of uniform ovoid darkstaining basaloid cells with moderate-sized nuclei and little cytoplasm. The cells are arranged into well-demarcated islands and strands, which appear to arise from the basal cell layer of the overlying epidermis that invade the underlying dermal connective tissue. Epithelial islands typically demonstrate palisading of the peripheral cells. A clear zone of artifactual retraction is seen between the epithelial islands and the connective 
tissue. In pigmented type of $\mathrm{BCC}$, melanocytes are seen within tumor islands. Sclerosing BCC is characterized by strands of basaloid tumor cells in a densely collagenous background. Superficial BCC includes lobules of tumor cells that drop from the epidermis in a multifocal pattern. ${ }^{(3,4)}$ The patient files with incomplete information and without definite diagnosis of the lesions and the ones related to the recurrence of the lesion were excluded. The data were entered into SPSS 19 software and were analyzed using descriptive statistical methods (mean, standard deviation, frequency and percentage), mean comparisons, and Chi-Square test.

\section{Result:}

In this study, 205 subjects with the average age of $69.7 \pm 10.2$ years were examined. Minimum and maximum ages of the patients were 47 and 95 years, respectively. Most cases were between 63 to 78 years old (47.3\%). 114 cases $(55.6 \%)$ were males and 91 subjects $(44.4 \%)$ were females (Table 1).

Tabel 1- The age group under review

\begin{tabular}{lcc}
\hline Variable (age) & Number & $\mathbf{\%}$ \\
\hline $47-62$ year-olds & 50 & $24.4 \%$ \\
\hline $63-78$ year-olds & 97 & $47.3 \%$ \\
\hline $79-95$ year-olds & 58 & $28.3 \%$ \\
\hline
\end{tabular}

The highest incidence of the lesion was detected in the frontal region (23.9\%), while the lowest incidence was found in the neck $(7.8 \%)$.

(Table 2)
Table 2- Incidence rates of $\mathrm{BCC}$ in different regions of the head and neck

\begin{tabular}{|c|c|c|}
\hline $\begin{array}{c}\text { Variable } \\
\text { (location of the lesion) }\end{array}$ & Number & $\%$ \\
\hline nasal & 25 & $12.2 \%$ \\
\hline zygomatic & 33 & $16.1 \%$ \\
\hline frontal & 49 & $23.9 \%$ \\
\hline preoral & 17 & $8.3 \%$ \\
\hline preauricular & 22 & $10.7 \%$ \\
\hline neck & 16 & $7.8 \%$ \\
\hline temporal & 43 & $21 \%$ \\
\hline Total & 205 & \\
\hline
\end{tabular}

The most frequently encountered clinical variant of BCC was the nodular type (57.1\%), while the lowest incidence was related to the pigmented type $(8.3 \%)$. Among the microscopic variants, the highest frequency was related to the solidcystic variant $(57.1 \%)$, while the pigmented type showed the lowest frequency (7.3\%). (Table 3 )

Table 3- Microscopic variants of BCC in the head and neck based on gender

\begin{tabular}{rcccc}
\hline & Variable & \multicolumn{2}{c}{ Gender } & p-value \\
\cline { 1 - 4 } & & Male & Female & \\
\hline \multirow{3}{*}{$\begin{array}{c}\text { Histologic } \\
\text { views }\end{array}$} & Solid-cystic & 61 & 56 & $\mathrm{P}=0.24$ \\
\cline { 2 - 5 } & Pigmented & 8 & 7 & $\mathrm{P}=0.24$ \\
\cline { 2 - 5 } & Superficial & 15 & 15 & $\mathrm{P}=0.24$ \\
\cline { 2 - 5 } & Morpheaform & 16 & 5 & $\mathrm{P}=0.24$ \\
\hline
\end{tabular}

(Figures 1 to 4) There was no significant correlation between the location of the lesion in men and women $(\mathrm{p}=0.14)$ or between the location of the lesion and age. $(\mathrm{p}=0.16)$ (Table 4$)$ 
Table 4- Clinical variants of $\mathrm{BCC}$ in the head and neck based on gender

\begin{tabular}{lcccc}
\hline \multirow{2}{*}{} & Variable & \multicolumn{2}{c}{ Gender } & p-value \\
\cline { 2 - 4 } & & Male & Female & \\
\hline \multirow{3}{*}{$\begin{array}{l}\text { Clinical } \\
\text { variants }\end{array}$} & Nodular & 61 & 56 & $\mathrm{P}=0.18$ \\
\cline { 2 - 4 } & Ulcerative & 27 & 22 & $\mathrm{P}=0.18$ \\
\cline { 2 - 4 } & Pigmented & 9 & 8 & $\mathrm{P}=0.18$ \\
\cline { 2 - 4 } & Sclerosing & 17 & 5 & $\mathrm{P}=0.18$ \\
\hline
\end{tabular}

The correlation between the microscopic variants of BCC and gender was statistically significant $(\mathrm{p}=0.03)$. Likewise, the correlation between the clinical variants of $\mathrm{BCC}$ and gender was statistically significant $(\mathrm{p}=0.01)$. The statistical approach of the present study was to assess the degree of $95 \%$.

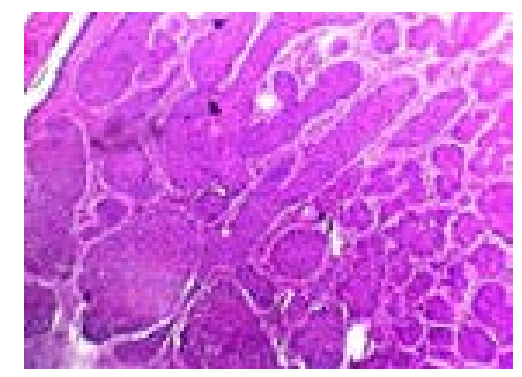

Figure 1- Solid-cystic BCC (H\&E staining, magnification $\times 20$ )

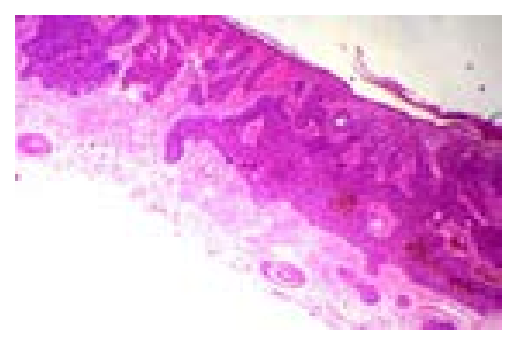

Figure 2- Pigmented BCC (H\&E staining, magnification $\times 20$ )

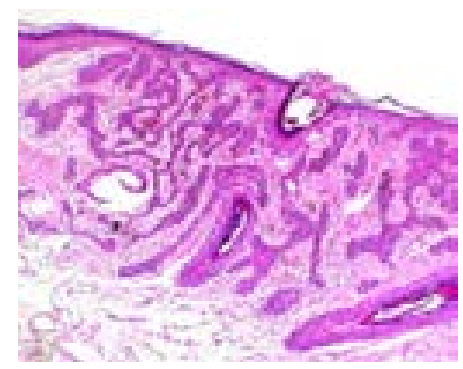

Figure 3- Superficial BCC (H\&E staining, magnification $\times 20$ )

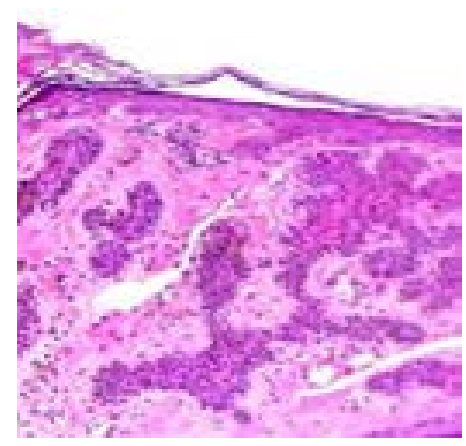

Figure 4- Sclerosing (morpheaform) BCC (H\&E staining, magnification $\times 20$ )

\section{Discussion:}

The results of the current study showed that most patients were between 63 to 78 years old (47.3\%). Some studies have indicated that the disease is more common in those aged over 40 years. ${ }^{(14,15)}$ Jurciukonyte et al and Vantuchová et al have reported the incidence rates of $75 \%$ and $65 \%$ in men, respectively ${ }^{(16-17)}$, which is consistent with the results of the present study. $55.6 \%$ of the subjects were males, similar to the study that has reported the prevalence of the lesion to be $30 \%$ higher in males. ${ }^{(3,18)}$ This is also consistent with the results of the studies that have reported higher incidence rates of this cancer in men. ${ }^{(4,15,19)}$ The results of the present study indicated that the most common location of BCC was the frontal region (23.9\%), which contradicts the results of the study that has reported the nasal area as the most common location for this lesion $(27.4 \%) .^{(15)}$ In the present study, the most frequent microscopic view of BCC was related to the nodular type $(57.1 \%)$, which was also the most common variant in 
both women and men. This result confirms the results of previous studies, which indicated that the most common clinical form of the lesion is the nodular type..$^{(1,6,15,18,20)}$

The most common location of the lesions was the temporal area in men, which was similar to the results of the study by Puizina-Ivic et al that reported the incidence of $14.6 \%{ }^{(14)}$ The most common location of the lesion in women was the forehead, similar to the results of a study that declared the incidence of $8.7 \% .^{(13)}$ This result was incompatible with the results of the study that reported the cheeks to be the most common location of the lesion in women. ${ }^{(16)}$ The results indicated that due to direct exposure to sunlight, the temporal area in men tends to show the highest incidence of the lesions, whereas the incidence of the lesions in this area is low in women, as it is often covered by hair or a scarf. The most common microscopic variant of BCC was the solidcystic type in both males and females, similar to the results of previous studies. ${ }^{(13,15,17)}$

Most authors believe that the nodular type of BCC has a low tendency for local recurrence, while the superficial type is high risk in this regard. According to previous studies, the nodular type comprises $75 \%$ of all BCCs. ${ }^{(4,10,11)}$ Similar results were achieved in the present study. Treatment methods for BCC include: surgical excision, mohs surgery, cryosurgery, chemotherapy and radiation..$^{(1,9,13)}$ The nodular variant has a better prognosis than the other subtypes. ${ }^{(4,8)}$

\section{Conclusion:}

The results of this study showed that the most common clinical variant of BCC was the nodular type, while the least common type was the pigmented variant.

The most common histological type was the solid-cystic type, while the pigmented form was the least common variant.

\section{Acknowledgements:}

This research was supported by Ilam University of Medical Sciences, Iran.

This research project was approved by the research council of Ilam University of Medical Sciences with the ID number 910927.

\section{Conflicts of Interest:}

The authors of this manuscript certify that they have no conflicts of interest regarding this research.

\section{References:}

1.Piccinno R, Benardon S, Gaiani FM, Rozza M, Caccialanza M. Dermatologic radiotherapy in the treatment of extensive basal cell carcinomas: a retrospective study. J Dermatolog Treat 2017; 29:1-5.

2.Bettencourt MS. Treatment of superficial basal cell carcinoma with ingenolmebutate gel, $0.05 \%$. Clin Cosmet Investig Dermatol 2016;16(9):2059.

3.Lubeek SF, van Vugt LJ, Aben KK, van de Kerkhof PC, GerritsenMP.The Epidemiology and Clinicopathological Features of Basal Cell Carcinoma in Patients 80 Years and Older: A Systematic Review.JAMA Dermatol 2016;12(2):28-33.

4.Doan HQ, Silapunt S, MigdenMR.Sonidegib, a novel smoothened inhibitor for the treatment of advanced basal cell carcinoma.Onco Targets Ther 2016;14(9):5671-8.

5.Shahsavari F, Sadri D, Jolehar M, Farzanehnejad R. Epidemiologic Study of the Prevalence of Oral Mucosal Lesions in the Biopsied Samples at Buali and Imam Khomeini Hospitals from 2000 to 2014. J Res Dentomaxillofac Sci 2016;1(1):2833.

6.Lorimer P, MilasZ .Cutaneous manifestations associated with malignancy of the head and neck. Semin Oncol 2016;43(3):353-8.

7.Lohuis PJ, Joshi A, Borggreven PA, Vermeeren L, Zupan-Kajcovski B, Al-Mamgani A, Balm AJ.Aggressive basal cell carcinoma of the head and neck: challenges in surgical management. Eur Arch Otorhinolaryngol 2016;273(11):3881-9. 8. Chun KA, Cohen PR. Basal Cell Carcinoma of the Nipple-Areola Complex: A Comprehensive Review of the World Literature Dermatol Ther (Heidelb) 2016;6(3):379-95. 
9.Radhakrishnan S, Adulkar NG, Kim U. Primary cutaneous histoplasmosis mimicking basal cell carcinoma of the eyelid: A case report and review of literature. Indian J PatholMicrobiol 2016;59(2):227-8.

10.Lanoue J, Goldenberg G .Basal Cell Carcinoma: A Comprehensive Review of Existing and Emerging Nonsurgical Therapies. J Clin Aesthet Dermatol 2016;9(5):26-36.

11.Ceillary RI, Del Rosso JQ.Current modalities and new advances in the treatment of basal cell carcinoma .Int J Dermatol 2014;45(5):489-98.

12.Crowson AN. Basal cell carcinoma: biology, morphology and clinical implication, Mod Pathol 2006;19Suppl 2:S127-47.

13.Di Stefani A, ChimentiS. Basal cell carcinoma: clinical and pathological features. G Ital Dermatol Venereol 2015;150(4):385-91.

14.Puizina-Ivić N, Matoković B, Gluncić I, Maslovara S, Vela-Ljubić J. Histopathologic Variants of Basal Cell Carcinoma Correlation with Sex, Age and Localization. J Med Syst.1999;23(5):389-400.

15.Ulrich M. Optical coherence tomography for diagnosis of basal cell carcinoma: essentials and perspectives. Br J Dermatol 2016;175(6):1145-6.

16.Jurciukonyte R, Vincerzevskiene I, Krilaviciute A, Bylaite M, Smailyte G. Epidemiology of basal cell carcinoma in Lithuania, 1996-2010. Br J Dermatol 2013;169(5):1100-5.

17.Vantuchov á Y, Čuř́k R. Histological types of basal cell carcinoma. SCRIPTA MEDICA (BRNO) 2006;79(5-6):261-70 .

18.SharpHJ,PauG,DijkgraafGJ,etal.GenomicanalysisofsmoothenedinhibitorresistanceinBasalcellcarcinoma.Cancer Cell. 2015;27(3):327-35 .

19.de la Fouchardière A, Cabaret O, Savin L, Combemale P, Schvartz H, Penet C,etal. Germline BAP1 mutations predispose also to multiple basal cell carcinomas .Clin Genet 2015;88(3):273-7.

20.Prieto-Granada C, Rodriguez-Waitkus P. Basal cellcarcinoma: Epidemiology,clinical and histologic features, and basic science overview. Curr Probl Cancer 2015;39(4):198-205. 